\title{
CONSTRUÇÃO DE DESCRITORES PARA O PROCESSO DE EDUCAÇÃO PERMANENTE EM ATENÇÃO BÁSICA
}

\author{
BUILDING DESCRIPTORS FOR THE PERMANENT BASIC CARE EDUCATION PROCESS
}

\author{
Rosita Saupe ${ }^{1}$ \\ Luiz Roberto Agea Cutolo² \\ Juliana Vieira de Araújo Sandri ${ }^{3}$
}

Resumo Educação permanente e atenção básica fazem parte do sistema de saúde brasileiro desde suas origens. Recentemente estas políticas públicas foram atualizadas, gerando um movimento inovador de construção de conhecimento visando apoiar sua implementação e consolidação. Este estudo, através de uma metodologia quantitativa, procurou evidenciar os principais descritores que devem orientar os processos de educação permanente em atenção básica. O método é originário da Universidade da Carolina do Norte. É desenvolvido em duas etapas. Os dados apresentados neste artigo dizem respeito à primeira etapa, que inclui as seguintes fases: elaboração de um diagrama com todos os componentes a serem avaliados; sua análise por um grupo de especialistas, indicando o que deve ser mantido, retirado ou incluído; avaliação por juízes, utilizando escala Likert de 1 a 5; verificação da concordância entre os juízes. O diagrama foi decomposto em quatro dimensões, procurando responder as seguintes questões: para quem? audiências ou população alvo; o quê? - módulos de conteúdos e experiências de aprendizagem; para quê? - competências a serem desenvolvidas; e como? - metodologia a ser priorizada. Os resultados evidenciaram a procedência dos descritores propostos e avaliados, constituindo em material que pode contribuir para a tomada de decisão sobre educação permanente em atenção básica.

Palavras-chave atenção básica à saúde; educação permanente; descritores.
Abstract Permanent education and basic care have been part of the Brazilian health system from the beginning. These public policies were recently updated, leading to an innovative knowledge construction movement to support their implementation and consolidation. This study, which used a quantitative approach, attempted to single-out the main descriptors that must guide the permanent basic care education processes. The method originated at the University of North Carolina and is carried out in two stages. The data shown in this article concern the first stage, which includes these phases: elaboration of a diagram with all components to be assessed; analysis by a group of specialists, indicating what must be preserved, removed or included; evaluation by judges, based on the 1-to-5 Likert scale; verification of the agreement among the judges. The diagram was decomposed in four dimensions, seeking to answer these questions: for whom? audiences or target population; what? content modules and learning experiences; for what? competencies to be developed; and how? approach to be prioritized. The results showed the validity of the descriptors that were proposed and evaluated, a material that may contribute to decisionmaking regarding permanent basic care education. Keywords basic health care; permanent education; descriptors. 


\section{Introdução}

A complexidade da atenção à saúde das pessoas e populações vem demandando a incorporação de novas perspectivas às competências dos trabalhadores. Além da confirmação da necessidade cada vez maior de competência técnica e científica na especificidade de cada profissão, precisamos incorporar a capacidade de exercer e mediar parcerias que viabilizem o intercâmbio e o convívio interdisciplinar e interinstitucional, bem como revitalizar o resgate da humanização, da sensibilidade e da subjetividade nas relações entre as pessoas e com tudo que as cerca, fortalecendo as possibilidades de obter sucesso na arte de manejar as crises do cotidiano.

Por outro lado, é consenso na área que as instituições que lidam com a formação e a assistência têm dificuldade em implementar as mudanças necessárias para aproximar o processo formativo do processo de trabalho em freqüente descompasso com as demandas sociais por saúde. Neste contexto, a educação permanente não se apresenta apenas como possibilidade de iniciação ao trabalho ou de atualizações esporádicas, mas como processo perene de múltiplas aproximações ou, como propõe Furter (1974, p. 168), "diferentes aproximações (approachs) possíveis". O mesmo autor argumenta sobre o enfoque interdisciplinar necessário "para o estudo, a análise e a avaliação" da educação permanente. A interdisciplinaridade contribui de várias formas: ampliando os grupos a serem incluídos, implicando a intersetorialidade, a interinstitucionalidade e o controle social; revitalizando conteúdos a partir das experiências vivenciadas e assim ultrapassando o domínio técnico e científico especifico de cada profissão; aprofundando competências para o cuidado clínico individual, familiar e coletivo, para o planejamento, para a compreensão de informações epidemiológicas, para o gerenciamento compartilhado dos serviços e as relações entre profissionais e usuários; testando metodologias e tecnologias que favoreçam o exercício democrático nas 'rodas' de discussão e pactuação.

Desta maneira, a educação permanente estará acompanhado o avanço do conhecimento que proponha soluções viáveis para os problemas de saúde que constituem o cotidiano da atenção básica.

Mas é preciso também ter presente que os atores sociais, que constituem a dimensão privilegiada necessária para transformar idéias em ações, são 'sujeitos sujeitados' como Rovere (2005, p. 170) chama a atenção: “sujetados a modelos de formación, a modelos de práctica, a modelos de gestión, en definitiva a um habitus (grifo do autor citado), como diria Bourdieu, no es sencillo ni depende solo de un acto de voluntad".

No caso deste estudo ${ }^{4}$, este problema recebeu significativo reforço durante o desenvolvimento da pesquisa intitulada Competências dos Recursos Humanos em Saúde para consolidação do SUS/PSF. No processo da investi- 
gação emergiu, como tema recorrente, nos depoimentos dos 145 profissionais de saúde participantes, todos atuando em equipes de PSF, a importância da educação permanente para qualificar o processo de trabalho e as novas necessidades como atuação em equipe, gerenciamento, interdisciplinaridade, educação em saúde, bem como a capacitação para a produção de conhecimento na atenção básica. As políticas públicas em educação e saúde estão sendo sistematicamente orientadas para promover a aproximação entre formação e atenção na saúde, sinalizando a necessidade de se realizar estudos que auxiliem os gestores na tomada de decisão.

Nesta perspectiva, este estudo tem sua 'justificativa' vinculada à importância atribuída ao processo de educação permanente para mudança do modelo assistencial em saúde no Brasil, e seu 'objetivo' pretendeu ser atingido através da definição dos principais descritores indicados para a proposição e avaliação dos programas e projetos orientados para o processo de educação permanente na atenção básica em saúde. E, a partir destes descritores e da literatura, concluir, propondo um conceito para a educação permanente, que incorpore as várias dimensões do tema. Como descritor compreendemos uma palavra ou uma expressão que represente um determinado conceito que possa ser detalhado em seus componentes.

A pesquisa partiu dos conceitos e proposições ministeriais, incorporou a perspectiva dos pesquisadores e consultou 'especialistas' e 'juízes'. Logo, os resultados obtidos representam a compreensão de uma parcela de sujeitos que vivenciam diariamente as facilidades, dificuldades e conflitos que se apresentam na realidade do exercício de suas atividades, sejam elas docentes ou assistenciais. Entendemos ser uma importante contribuição na avaliação das políticas públicas, na perspectiva de seu aperfeiçoamento tanto como conceito quanto projeto operacional.

\section{Fundamentação teórica}

O significado do termo educação tem evoluído através dos tempos. Um olhar retrospectivo permite evidenciar este processo conforme apontam Harper et al. (1980). Para estes autores, nas sociedades primitivas o que se ensina e o que se aprende devem servir de algum modo a todos. Este caráter coletivo permanece na Grécia e Roma antigas, onde a educação devia formar o homem político, o cidadão da pólis, a serviço da comunidade. Já no Mundo Ocidental, desde a Antigüidade decadente, passando pela Idade Média, Renascimento e alcançando a Idade Moderna, encontramos o Estado ideologicamente cristianizado, que isola o saber da sociedade e o submete ao destino individual do cristão: filhos de nobres aprendem em casa com preceptores; os escravos livres, artistas pobres e artesãos aprendem no oficio, 
na oficina. Somente no início do século XX começa a aparecer o reconhecimento do direito à educação para todos e como dever do Estado (Brandão, 1993). Na atualidade, a educação parece incorporar tanto a perspectiva individual quanto a coletiva. Constitui importante dimensão da vida, necessária à participação social e requisito indispensável para acesso e permanência no mundo do trabalho. A educação se tornou permanente e uma das facetas do nosso cotidiano.

No caso da saúde, educação permanente e atenção básica fazem parte do sistema brasileiro desde suas origens e a questão conceitual tem sido uma das preocupações de intelectuais (Ceccim e Feuerwerker, 2004; Ceccim, 2005; Merhy, 2005; Rovere, 2005) comprometidos com o tema. Assim, verificamos que denominações como treinamento em serviço, educação no trabalho, educação em serviço, educação continuada, educação permanente são conceitos que foram se apresentando na área da saúde, mas mantendo significados entre si. Estas nomenclaturas têm incluído tanto os programas pontuais de capacitação inicial para o trabalho ou atualização científica e tecnológica, logo transitórios, como os departamentos permanentes que compõem os organogramas oficiais das instituições de saúde, especialmente na área hospitalar.

Essa reflexão foi corroborada por Ferraz (2005), ao considerar que existe controvérsia entre os autores que consultou e que, semanticamente, as palavras continuada e permanente possuem o mesmo sentido, levando-a a optar por usar, em sua dissertação, a denominação permanente/continuada. Na mesma perspectiva, Pereira e Monteiro (2007), ao analisarem a Política Nacional de Educação Permanente em Saúde, colocam que tanto o conceito teórico quanto o metodológico da educação permanente ainda não ficaram efetivamente compreendidos, levando a inferir a necessidade de investigação e mais reflexão sobre o tema.

Todavia, as políticas públicas que embasaram todas as etapas desta pesquisa estão fundadas em uma concepção que estabelece clara diferenciação entre 'educação continuada' e 'educação permanente' e que ultrapassa a questão semântica. Esta diferenciação se inicia pelo processo participativo de construção destas políticas, que começa a se delinear desde as primeiras conferências nacionais de Saúde e de Recursos Humanos, em especial as realizadas no ano de 1986, permeia todo o movimento da Reforma Sanitária e se consolida com a criação do Sistema Único de Saúde (SUS) em 1990. Ribeiro e Motta (1996, p. 3) apóiam esta diferenciação quando afirmam que "a produção teórica sobre o campo da educação permanente permite que se faça uma distinção clara e inequívoca entre educação continuada e permanente".

Apesar de centradas somente na perspectiva dos trabalhadores como sujeitos da educação permanente, as diferenças apontadas por Ribeiro e 
Motta (1996) ajudam a iluminar os conceitos. Os autores afirmam que a educação continuada é unidirecional, orientada para a prática autônoma, tem enfoque em especialidades, com objetivo central na atualização técnica e científica, com periodicidade esporádica, usa a pedagogia da transmissão e busca a apropriação passiva do saber. Já a educação permanente tem perspectiva multiprofissional, está voltada para a prática institucionalizada, com enfoque nos problemas de saúde, objetivando transformações nas práticas, ininterrupta no tempo, usando da pedagogia problematizadora e espera, como resultados, a mudança institucional, a apropriação ativa do saber cientifico e o fortalecimento das ações em equipe.

A contribuição de Ceccim (2004) para o debate conceitual avança significativamente. Inicia apresentando os vários termos e seus significados, conforme diferentes atores sociais compreendem a educação permanente em saúde. Assim, para alguns ela pode corresponder à educação em serviço; à educação continuada; à educação formal de profissionais; a um desdobramento da educação popular, ou da educação de jovens e adultos, ou do movimento institucionalista em educação; e ainda representar o pensamento de vários movimentos de mudança. Após descrever estas várias interpretações, destaca “que aquilo que deve ser realmente central à Educação Permanente em Saúde é sua porosidade à realidade mutável e mutante das ações e dos serviços de saúde". Esta porosidade tem a ver principalmente com mudança, tanto nos perfis profissionais quanto nas instituições (Ceccim, 2004, p. 162).

Recentemente as políticas públicas relacionadas ao processo de educação permanente em saúde foram atualizadas, gerando um movimento inovador de construção de conhecimento visando apoiar sua implementação e consolidação. Este movimento de renovação está ancorado especialmente na Secretaria de Gestão do Trabalho e da Educação na Saúde (SGTES), criada pelo decreto $\mathrm{n}^{\circ} 4.726$, de 9 de junho de 2003. Esta iniciativa, que pode ser considerada 'um divisor de águas' no que diz respeito à educação permanente em saúde, ainda é muito recente e requer empenho dos atores envolvidos para que seus objetivos sejam alcançados. Vale a pena lembrar os dois grandes objetivos desta secretaria, vinculada ao Ministério da Saúde: 1) motivar e propor a mudança na formação técnica, de graduação e de pós-graduação e um processo de educação permanente dos trabalhadores da saúde, a partir das necessidades de saúde da população e de fortalecimento do Sistema Único de Saúde (SUS); 2) valorizar e fortalecer a participação e a democracia nas relações de trabalho, estabelecendo propostas de desprecarização do trabalho em saúde, de um plano de carreira para o SUS, com definição de vínculos e carreiras que assegurem direitos dos trabalhadores e a presença do Estado na condução das políticas de saúde (Brasil, 2007). 
Para atingir estes objetivos, a SGTES está organizada em dois departamentos: 1) o Departamento de Gestão da Educação na Saúde (Deges), que coordena ações estratégicas e técnicas em educação na saúde, e 2) o Departamento de Gestão e da Regulação do Trabalho em Saúde (Degerts), que coordena a gestão, a regulação e a negociação do trabalho em saúde.

Estão vinculadas à SGTES tanto a Rede Observatório de Recursos Humanos de Saúde (Rorehs) como a Mesa Nacional de Negociação Permanente do SUS (MNNP-SUS), reafirmando sua política de participação, negociação e pactuação. A construção do principal documento legal, no que diz respeito à educação permanente, a portaria $n^{\circ}$ 198/GM/MS, de 13 de fevereiro de 2004, seguiu este percurso. A introdução do anexo 2 à portaria afirma que as orientações e diretrizes para operacionalização da Política Nacional de Educação Permanente em Saúde, como estratégia do SUS para a formação e o desenvolvimento dos trabalhadores para o setor, foi elaborada a partir de vários documentos amplamente discutidos e objeto de consenso, destacando:

- A Política de Formação e Desenvolvimento para o SUS: caminhos para a Educação Permanente em Saúde, aprovada pelo plenário do Conselho Nacional de Saúde (CNS), em 4 de setembro de 2003.

- A Estratégia Pólos de Educação Permanente em Saúde, que reconhece as instâncias locorregionais e interinstitucionais de gestão da Educação Permanente em Saúde, pactuada pela Comissão Intergestores Tripartite, em 18 de setembro de 2003.

- A resolução do Conselho Nacional de Saúde, n 335, de 27 de novembro de 2003, que aprova os documentos citados (Brasil, 2004).

A estratégia para condução locorregional da Política Nacional de Educação Permanente em Saúde está assentada no Colegiado de Gestão, configurado como Pólo de Educação Permanente em Saúde para o SUS, instância interinstitucional, denominada de 'roda' de gestão, com as funções de coordenar todas as ações de educação permanente em seu território adscrito.

Debatendo sobre a temática, Merhy (2005) aborda os Pólos de Educação Permanente e suas possibilidades na construção da necessária problematização, chamando a atenção para o fato de que os mesmos "não necessariamente respondem de modo uniforme" a pauta nacional no que diz respeito tanto à "mudança do conjunto das práticas dos gestores da saúde quanto a suas intervenções no campo da educação em saúde (...) pois a instalação de múltiplos atores locorregionais lhe dão singularidades que não podem ser desprezadas" (Merhy, 2005, p. 173). Entendemos que este é um aspecto importante, na medida em que a aderência ao 'fio condutor' nacional não impossibilita atender as particularidades locais e regionais, flexibilizando o processo de educação permanente na saúde. 
Avançando na perspectiva de operacionalizar o processo de educação permanente em saúde, Ceccim e Feuerwerker (2004, p. 43), após criticarem a formação em saúde que temos feito no Brasil e a necessidade de reforma da educação, afirmam que a mesma "deveria ter como objetivos a transformação das práticas profissionais e da própria organização do trabalho, e estruturar-se a partir da problematização do processo de trabalho". Para isso propõem uma prática de experimentação, fundada no conceito de quadrilátero da formação, que inclui o ensino, a gestão, a atenção e o controle social.

As idéias e propostas dos pensadores, militantes do movimento pela Reforma Sanitária no Brasil e articulistas, aqui apresentadas, bem como os diplomas legais que têm sido construídos e implementados na área da saúde, ofereceram a fundamentação teórica para este estudo. O diálogo com os mesmos iluminou o percurso metodológico e a discussão dos dados.

\section{Metodologia}

O método utilizado é originário da Universidade da Carolina do Norte, desenvolvido no início da década de 1970, introduzido no Brasil em meados da mesma década e utilizado por Spínola e Pereira (1977) para avaliação do Programa do Imposto de Renda Brasileiro de 1977. Consta de duas grandes etapas, cada uma dividida em fases. Os dados apresentados neste artigo correspondem à aplicação da primeira etapa que foi desenvolvida em quatro fases.

Na primeira fase, os pesquisadores, a partir da fundamentação teórica delimitada, amparados pela literatura, e considerando suas experiências profissionais, construíram um mapa no formato de diagrama de árvore, incluindo as dimensões e os vários descritores que consideravam importantes para o processo de educação permanente na área da saúde.

Em seguida, na segunda fase, este modelo foi submetido a um grupo de peritos 'especialistas' no assunto, para que avaliassem a importância de cada um dos componentes no conjunto apresentado e sugerissem o que deveria ser mantido, acrescido ou retirado. Conforme o conceito proposto por Deleuze (1992), um campo que está sendo mapeado está aberto e sensível à incorporação de contribuições e significações. Os peritos consultados foram: um médico com 32 anos de experiência em atenção básica e 3 anos em educação permanente; uma enfermeira com atuação direta na atenção básica por cerca de 7 anos, coordenando processos participativos e participando da equipe da Secretaria Estadual de Saúde, do estado de Santa Catarina, nas questões de educação permanente; um odontólogo com 17 anos em atenção básica e participante de processos de educação permanente. Todos 
são considerados altamente qualificados por seus pares e militantes ativos no processo da Reforma Sanitária. As sugestões destes 'especialistas' foram incorporadas ao diagrama de árvore, gerando modificações que foram aceitas pelos pesquisadores, resultando no Diagrama 1.

Na terceira fase, denominada 'método do júri', um grupo ímpar, no caso 21 , número já testado em projeto anterior e que possibilitou diversidade adequada (Saupe et al., 2005) de especialistas, foi solicitado, individualmente, a atribuir pesos a cada componente do diagrama, conforme uma escala com valores de 1 a 5, previamente apresentada ao mesmo. O peso 1 representa um valor 'muito baixo', o peso 2 é associado a um valor 'baixo'; o peso 3 corresponde ao valor 'mediano'; o peso 4 ao valor 'alto'; e, finalmente, o peso 5 ao valor 'muito alto'. A caracterização deste grupo indica que, quanto à profissão, o mesmo foi composto por 7 enfermeiros, 6 odontólogos, 4 médicos, 2 fisioterapeutas, 1 farmacêutico e 1 fonoaudiólogo. Quanto ao tempo de formado, estes profissionais se situaram na faixa entre 2 e 32 anos, com média de 17 anos, evidenciando a diversidade desejada de incluir trabalhadores com experiências diferenciadas. A tendência de investir em seu processo de educação permanente também foi comprovada, pois um único juiz era somente graduado e outro especialista, sendo que 14 possuíam mestrado e cinco já estavam titulados no nível de doutorado.

A quarta fase é a 'verificação da concordância entre os juízes'. Esta concordância ocorre naturalmente quando 'todos' os juízes atribuem os mesmos valores ao mesmo componente do diagrama. No caso de não-concordância, foi usada a mediana para estabelecer o valor da avaliação. Como nenhum dos componentes incluídos no diagrama de árvore e submetido à avaliação pela escala Likert apresentada na metodologia recebeu a mesma nota de todos os juízes, a concordância foi estabelecida pela mediana dos valores atribuídos, conforme apresentado na seqüência.

O projeto relativo a este estudo foi aprovado pela $17^{\text {a }}$ Regional de Saúde do Estado de Santa Catarina, incluindo o aval dos prefeitos dos 11 municípios que a compõem, local da realização da pesquisa. Foi também registrado no Sistema Nacional de Ética em Pesquisa (Sisnep) e aprovado pela Comissão de Ética da Universidade do Vale do Itajaí, sob número 46/2006. Todos os cuidados éticos foram assegurados aos participantes que, após serem esclarecidos sobre detalhes do projeto, livremente assinaram Termo de Consentimento Livre e Esclarecido, os quais se encontram em nosso poder. O projeto incluiu também Termo de Compromisso de Utilização de Dados e compromisso de retorno dos resultados às instituições envolvidas. 


\section{Resultados}

A construção dos descritores foi concretizada no diagrama de árvore (Diagrama 1). Resultou numa composição com quatro dimensões, que procuraram responder as seguintes questões: para quem? - audiências ou população alvo; o quê? - módulos de conteúdos e experiências de aprendizagem; para quê? - competências a serem desenvolvidas; e como? - metodologia a ser priorizada. O detalhamento destas dimensões procurou aproximação com o quadrilátero proposto por Ceccim e Feuerwerker (2004), focalizando o ensino, a gestão, a atenção e o controle social.

\section{Diagrama 1}

Descritores e suas respectivas medianas, conforme avaliação dos juízes

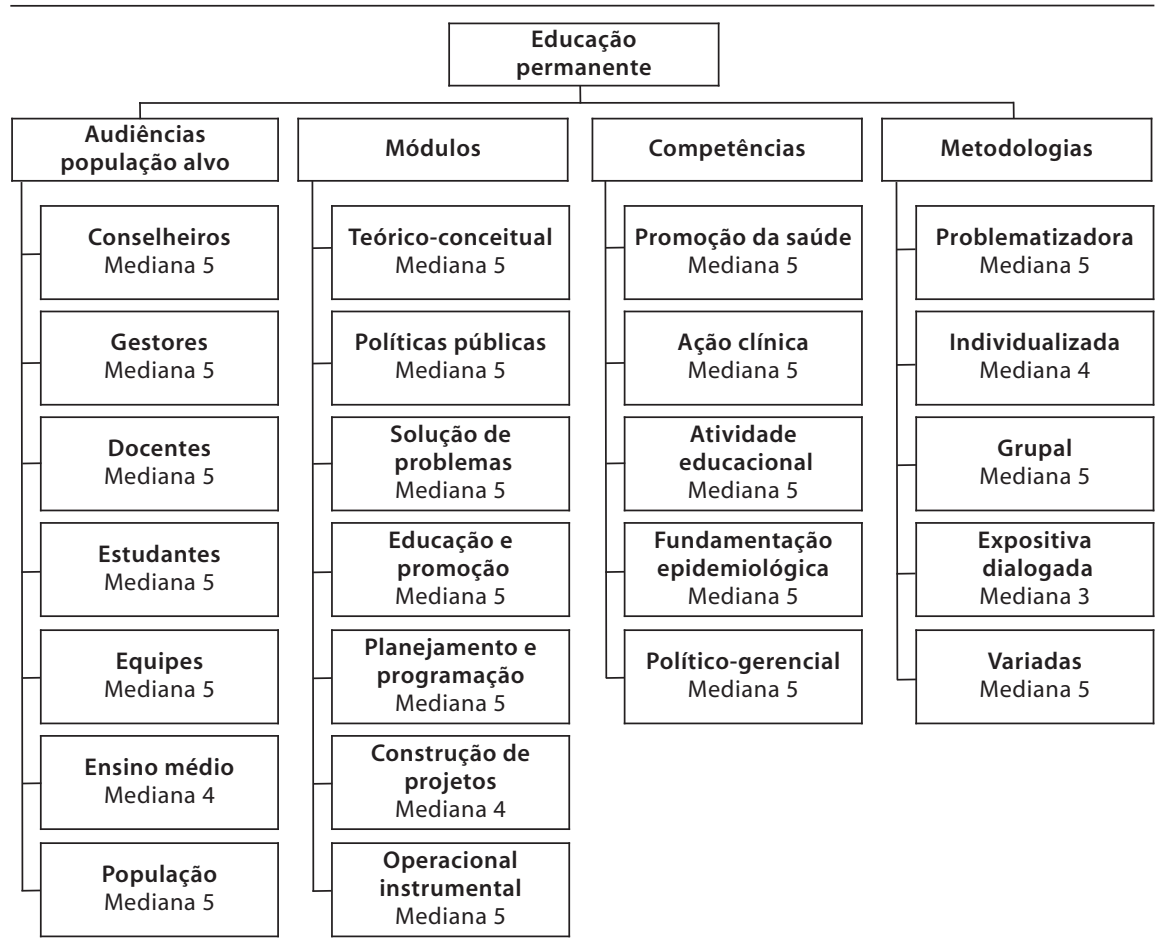

A delimitação das 'audiências' ou população alvo dos programas de educação permanente, para este estudo, partiu da definição oficial dos atores que atuam no setor saúde e que incluem: os gestores municipais e estaduais do SUS, as instituições de ensino, os centros formadores do SUS, os estudantes das profissões de saúde, os conselhos municipais e estaduais da saúde, os movimentos sociais ligados à saúde, e os trabalhadores que atuam 
em saúde (Brasil, 2003; 2004; 2005a). Após a submissão da proposta original aos 'especialistas' foi sugerida a delimitação destas audiências e certa hierarquização, já que consideraram que o processo de educação permanente deveria atingir: prioritariamente conselheiros (principalmente os vinculados aos conselhos municipais e locais de saúde); em seguida, gestores (incluindo todos os níveis da gestão pública municipal na área da saúde); docentes (de cursos universitários e profissionais), com ênfase nos cursos que já formam profissionais inseridos na Estratégia de Saúde da Família (ESF); depois, estudantes da saúde (através de temas transversais, eventos, feiras de conhecimento, estágios extracurriculares; equipes de trabalhadores (grupos de profissionais que atuam na ESF); e, num terceiro nível de prioridade, o ensino médio (cursos técnicos na área da saúde); e a população (programas de educação em saúde voltados para grupos, famílias e coletividades). Apesar da Coordenação Geral de Ações Populares de Educação em Saúde ter sido transferida, em agosto de 2005, da SGTES, para a Secretaria de Gestão Participativa e Estratégica (SGPE), ficando vinculada ao Departamento de Apoio à Gestão Participativa (Brasil, 2007), os especialistas consideram a importância desta audiência e também que devem ser estimulados processos educativos que integrem esforços entre a SGTES e a SGPE.

Esta hierarquização foi justificada em função do poder de transformação das práticas de saúde, vinculado a cada uma das categorias. Uma sugestão bem interessante, formulada por um dos 'especialistas', chamou a atenção para a necessidade de serem realizadas 'oficinas coletivas', ou seja, a ultrapassagem de projetos direcionados a audiências especificas, possibilitando a participação de várias categorias num mesmo projeto ou módulo, visando integração e compartilhamento de problemas e soluções.

Esta proposta de 'audiências', submetida aos 21 juízes, recebeu a avaliação apresentada na Tabela 1 . A análise restrita às medianas obtidas não revela detalhes que a distribuição dos pesos atribuídos pelos juizes evidencia. Neste caso encontramos que a população alvo que obteve o maior consenso, podendo ser confirmada como audiência preferencial, foi aquela composta pelas equipes, logo seguida pelos gestores. Esta tendência confirma a política do Ministério da Saúde, que tem investido mais significativamente nestes grupos. Todavia, o preparo dos conselheiros de saúde também tem recebido investimentos importantes, mas, na avaliação dos juízes, foi superado por necessidades vinculadas aos docentes, o que parece refletir um pensamento bastante referido de que, para mudar a assistência, é preciso avançar na inclusão de docentes comprometidos com a atenção básica, ou de que, enquanto não mudarmos a formação dos trabalhadores da saúde, as dificuldades de transformação do modelo assistencial serão mais complexas. E mais, pois “muitas vezes, cursos necessários ao pessoal de serviços 
são ainda mais necessários ao pessoal docente para instalar sustentabilidade pedagógica locorregional" (Brasil, 2003, p. 6).

\section{Tabela 1}

Distribuição dos valores da Escala Likert atribuídos pelos juízes aos descritores da dimensão 'audiências' ou população alvo

\begin{tabular}{|c|c|c|c|c|c|c|c|c|}
\hline \multirow[t]{2}{*}{ No } & \multirow[t]{2}{*}{ Descritores } & \multirow[t]{2}{*}{ Mediana } & \multicolumn{5}{|c|}{ Pesos Escala Likert } & \multirow[t]{2}{*}{ Total } \\
\hline & & & 1 & 2 & 3 & 4 & 5 & \\
\hline 01 & Conselheiros & 5 & 0 & 0 & 2 & 6 & 13 & 21 \\
\hline 02 & Gestores & 5 & 0 & 0 & 0 & 4 & 17 & 21 \\
\hline 03 & Docentes & 5 & 0 & 0 & 1 & 5 & 15 & 21 \\
\hline 04 & Estudantes & 5 & 0 & 0 & 4 & 6 & 11 & 21 \\
\hline 05 & Equipes & 5 & 0 & 0 & 0 & 1 & 20 & 21 \\
\hline 06 & Ensino médio & 4 & 0 & 0 & 4 & 10 & 7 & 21 \\
\hline 07 & População & 5 & 1 & 2 & 6 & 4 & 8 & 21 \\
\hline \multicolumn{2}{|c|}{ Total } & & 1 & 2 & 17 & 36 & 91 & 147 \\
\hline
\end{tabular}

Nota: Peso 1= valor 'muito baixo'; Peso 2=valor 'baixo'; Peso 3=valor 'mediano'; Peso 4=valor 'alto'; Peso 5= valor 'muito alto'

O Ministério da Saúde lançou, em 2005, o Programa Nacional de Reorientação da Formação Profissional em Saúde (Pró-Saúde). Este programa busca a aproximação entre a formação de graduação no país e as necessidades da atenção básica, que no Brasil se traduzem pela Estratégia de Saúde da Família (Brasil, 2005b). É importante que a formação do profissional de saúde atenda as necessidades do mercado de trabalho, principalmente para o atendimento no SUS, desta forma é compreensível que, na avaliação dos juízes, os docentes e estudantes tenham obtido uma audiência significativa.

A formulação dos pesquisadores de que a educação permanente deve ser oferecida em 'módulos' foi aprovada pelos 'especialistas'. Entendemos por módulo um conjunto de conhecimentos, habilidades e atitudes, que pretendem atingir um objetivo específico, mas sempre articulado aos demais módulos de uma proposta pedagógica. O módulo transita entre a autonomia que lhe possibilita o seu objetivo e a dependência em relação ao conjunto do processo educacional. A definição dos módulos e seus componentes se pautou pelas orientações dos documentos que compõem as políticas públicas que fundamentam o estudo (Brasil, 2003; 2004; 2005a) com os devidos recortes considerados pelos pesquisadores. Importante salientar que os descritores que compõem os vários módulos necessitam serem ajustados a cada audiência específica, respeitadas suas necessidades e nível de escolarização, visando à compreensão e incorporação. Assim, temos como descritores basais: 
- O módulo 'teórico conceitual', focalizado na sensibilização para a mudança do modelo assistencial, incluindo fundamentação teórica sobre saúde, gestão, controle social e cuidado. Este módulo deve direcionar a perspectiva dos demais.

- O módulo voltado às 'políticas públicas', abordando não somente o sistema de saúde brasileiro, mas também de outros países, oportunizando análises comparativas.

- O módulo orientado para a 'solução de problemas da base territorial', que prevê a intervenção para enfrentamento de situações agudas e crônicas encontradas nas áreas geográficas de atuação das equipes. Pode ser integrado ao módulo 'construção de projetos', especialmente indicado para atingir objetivos relacionados aos problemas mais constantes, já que as emergências precisam de estratégias mais rápidas para serem colocadas em prática.

- O módulo denominado 'educação e promoção da saúde', caracterizado pelo desenvolvimento de metodologias para a educação em saúde e a educação permanente, bem como para a implementação de iniciativas e programas para a promoção da saúde.

- O módulo 'planejamento e programação', trazendo teorias, modelos e métodos para planejamento, desenvolvimento e avaliação de programas.

- O módulo 'construção de projetos', centrado principalmente em 'como' se constrói um projeto. Já a orientação quanto aos projetos em si ressalta temas que potencializem as ações, promovam impacto na saúde das pessoas, dêem mais continuidade às atividades, busquem soluções para os problemas crônicos das comunidades e possibilitem ajustes permanentes com base em avaliação contínua.

- O módulo 'operacional-instrumental', orientado para o processo de trabalho e desenvolvimento de modelos para: o cuidado, tecnologias, gerenciamento, investigação.

Tabela 2

Distribuição dos valores da Escala Likert atribuídos pelos juízes aos descritores da dimensão 'módulos'

\begin{tabular}{|c|c|c|c|c|c|c|c|c|}
\hline \multirow[t]{2}{*}{$\mathrm{N}^{\circ}$} & \multirow[t]{2}{*}{ Descritores } & \multirow[t]{2}{*}{ Mediana } & \multicolumn{5}{|c|}{ Pesos da Escala Likert } & \multirow[t]{2}{*}{ Total } \\
\hline & & & 1 & 2 & 3 & 4 & 5 & \\
\hline 01 & Teórico-conceitual & 5 & 0 & 0 & 2 & 6 & 13 & 21 \\
\hline 02 & Políticas públicas & 5 & 0 & 0 & 3 & 6 & 12 & 21 \\
\hline 03 & Soluções de problemas & 5 & 0 & 0 & 0 & 5 & 16 & 21 \\
\hline 04 & Educação e promoção & 5 & 0 & 0 & 1 & 3 & 17 & 21 \\
\hline 05 & Planejamento e programação & 5 & 0 & 0 & 2 & 5 & 14 & 21 \\
\hline 06 & Construção de projetos & 4 & 0 & 0 & 4 & 11 & 6 & 21 \\
\hline 07 & Operacional instrumental & 5 & 0 & 0 & 1 & 6 & 14 & 21 \\
\hline Total & & & 0 & 0 & 13 & 42 & 92 & 147 \\
\hline
\end{tabular}

Nota: Peso 1= valor 'muito baixo'; Peso 2=valor 'baixo'; Peso 3= valor 'mediano'; Peso 4= valor 'alto'; Peso $5=$ valor 'muito alto' 
Submetida aos 21 juízes convidados, estes módulos receberam os pesos apresentados na Tabela 2. Assim como verificado nos descritores apresentados na Tabela 1, a análise da avaliação dos módulos (Tabela 2) não pode se restringir às medianas obtidas, pois indica uma falsa homogeneidade. Apesar de a única mediana diferente ter ficado com 4, que representa um valor alto em uma escala de 1 a 5, a distribuição dos pesos atribuídos identifica uma situação bem diferenciada para o módulo 'construção de projetos'. Interessante este dado na medida em que trabalhar com projetos representa uma tendência atual de partir das necessidades reais, levantar recursos, estabelecer parcerias e implementar ações e é o modelo preconizado pelo Ministério da Saúde (Brasil, 2004) para a implantação de projetos de educação permanente através dos Pólos de Educação Permanente. No extremo oposto, com as melhores distribuições de pesos, temos 'educação e promoção' e 'solução de problemas', dois descritores que encontram, na nossa leitura, as melhores chances de sucesso quando desenvolvidos sob a forma de projetos.

Competência, apesar de não ser uma palavra original no discurso dos profissionais da saúde e de estar sujeita a inúmeras críticas, ganhou um novo status a partir de sua inclusão nas diretrizes curriculares (Almeida, 2003), gerando estudos visando ao esclarecimento do conceito (Saupe et al., 2006). As competências estabelecidas nas diretrizes curriculares estão apresentadas em dois blocos: específicas de cada categoria profissional e gerais, que são as mesmas para todos que atuam na área. As competências gerais incluem: atenção à saúde; tomada de decisões; comunicação; liderança; administração e gerenciamento; e educação permanente.

Para este estudo, as 'competências' a serem desenvolvidas têm o objetivo "de mejora de los servicios de salud (calidad, efectividad, eficiencia, equidad)" (OPS/OMS, 2002, p. 4) e incluem o preparo para: a "promoção da saúde' - programas e projetos para a promoção da saúde; a 'ação clínica' (individual, familiar e coletiva) - processo de cuidado às necessidades demandadas pelos usuários; as 'atividades educacionais' - desenvolvimento de programas de educação em saúde que gerem autonomia nas comunidades; a 'fundamentação epidemiológica' - capacitação para utilizar dados epidemiológicos para planejamento territorial; subsídios para mudança do conceito de saúde; a 'formação político-gerencial' - desenvolvimento e aplicação de instrumentos de gerenciamento dos serviços de saúde.

A relação entre este rol de competências, aprovado pelos autores, especialistas e juizes consultados, e aquelas estabelecidas nas diretrizes curriculares, aponta para uma maior aproximação com as competências gerais, que representam a importante inovação nos currículos que preparam profissionais da saúde. Esta constatação evidencia a afinação dos sujeitos desta pesquisa com as políticas públicas focalizadas neste estudo. 
Tabela 3

Distribuição dos valores da Escala Likert atribuídos pelos juízes aos descritores da dimensão 'competências' e mediana

\begin{tabular}{llllllllll}
\hline No & Descritores & Mediana & \multicolumn{9}{c}{ Pesos da Escala Likert } & Total \\
& & 5 & $\mathbf{1}$ & $\mathbf{2}$ & $\mathbf{3}$ & $\mathbf{4}$ & $\mathbf{5}$ & \\
\hline 01 & Promoção da saúde & 5 & 0 & 0 & 4 & 17 & 21 \\
02 & Ação clínica & 5 & 0 & 0 & 1 & 7 & 13 & 21 \\
03 & Atividades educacionais & 5 & 0 & 0 & 0 & 4 & 17 & 21 \\
04 & Fundamentação epidemiológica & 5 & 0 & 0 & 1 & 6 & 14 & 21 \\
05 & Formação político-gerencial & 5 & 0 & 0 & 1 & 5 & 15 & 21 \\
Total & & & 0 & 0 & 3 & 26 & 76 & 105 \\
\hline
\end{tabular}

Nota: Peso 1= valor 'muito baixo'; Peso 2=valor 'baixo'; Peso 3=valor 'mediano'; Peso 4=valor 'alto'; Peso $5=$ valor 'muito alto'

Na Tabela 3, verificamos que nenhum descritor obteve mediana inferior ao valor máximo, ficando em perfeita sintonia com a política nacional de educação permanente que "é uma proposta de ação estratégica que visa a contribuir para transformar e qualificar: a atenção à saúde, a organização das ações e dos serviços, os processos formativos, as práticas de saúde e as práticas pedagógicas" (Brasil, 2004, p. 9). Mas, a distribuição do peso 5 indica uma maior valorização da 'promoção da saúde' e 'atividades educacionais', o que também nos parece bastante adequado ao momento de ressignificação do conceito de saúde. Contudo, percebe-se que a 'a ação clínica' sobrepõe-se à 'fundamentação epidemiológica', tendência compreensível porque a formação dos profissionais de saúde, geralmente, oferece maior destaque ao conhecimento clínico em relação ao epidemiológico. Este fato é bastante observado na prática, na qual encontramos profissionais de saúde com dificuldades de planejar suas ações frente aos indicadores epidemiológicos de sua área de abrangência ou do seu espaço de trabalho.

Conforme Pereira e Monteiro (2007, p. 1), “a Educação Permanente em Saúde (EPS) é tida como estratégia para a aprendizagem a partir da problematização do processo de trabalho, onde o aprender e ensinar estão incorporados ao cotidiano das organizações e ao trabalho". A adoção da problematização nos projetos de educação permanente também é priorizada e inclusive definida pelo Ministério da Saúde (Brasil, 2005a, p. 7) para o qual "problematizar significa refletir sobre determinadas situações, questionando fatos, fenômenos e idéias, compreendendo os processos e propondo soluções". Para a OPS/OMS (2002, p. 4), a educação permanente em saúde parte da "problematización de las prácticas sanitarias (...) teniendo como mediador um proceso educativo que asegura aprendizajes significativos".

Assim, ao selecionarmos os descritores incluídos na dimensão 'metodologias', a 'problematização' foi priorizada, mas acompanhada de outras possibilidades de concretização dos processos educativos, já que a 
educação permanente não pode se reduzir a uma questão metodológica. Logo, entendemos que:

- A problematização implica co-responsabilidade entre os participantes em todas as etapas do processo de ensino e aprendizagem, com valorização do saber do educador e do educando.

- O ensino individualizado oportuniza que monitor ou tutor acompanhe, cada educando ou equipe, no desenvolvimento de projetos.

- O ensino grupal favorece atividades de construção e socialização coletiva do conhecimento.

- A aula expositiva dialogada facilita a apresentação de novos conceitos, modelos e métodos.

- $\quad$ O uso de métodos variados, representa uma possibilidade de adequação entre objetivos a serem atingidos, conteúdos a serem desenvolvidos e métodos a serem testados.

Tabela 4

Distribuição dos valores da Escala Likert atribuídos pelos juízes aos descritores da dimensão 'metodologias' e mediana

\begin{tabular}{|c|c|c|c|c|c|c|c|c|}
\hline \multirow[t]{2}{*}{ No } & \multirow[t]{2}{*}{ Descritores } & \multirow[t]{2}{*}{ Mediana } & \multicolumn{5}{|c|}{ Pesos da Escala Likert } & \multirow[t]{2}{*}{ Total } \\
\hline & & & 1 & 2 & 3 & 4 & 5 & \\
\hline 01 & Problematizadora & 5 & 0 & 0 & 0 & 2 & 19 & 21 \\
\hline 02 & Individualizada & 4 & 1 & 3 & 5 & 9 & 3 & 21 \\
\hline 03 & Grupal & 5 & 0 & 0 & 2 & 6 & 13 & 21 \\
\hline 04 & Expositiva dialogada & 3 & 0 & 5 & 10 & 5 & 1 & 21 \\
\hline 05 & Variadas & 5 & 0 & 0 & 4 & 3 & 14 & 21 \\
\hline \multicolumn{2}{|c|}{ Total } & & 1 & 8 & 21 & 25 & 50 & 105 \\
\hline
\end{tabular}

Nota: Peso 1= valor 'muito baixo'; Peso 2=valor 'baixo'; Peso 3=valor 'mediano'; Peso 4=valor 'alto'; Peso 5=valor 'muito alto'

A ênfase que o Ministério da Saúde tem dado ao desenvolvimento de projetos de educação permanente com a utilização de "metodologias ativas de ensino-aprendizagem" (Brasil, 2003) parece totalmente referendada pelos sujeitos desta pesquisa, conforme pode ser visualizado na Tabela 4. A metodologia 'problematizadora', apoiada por atividades grupais, provavelmente tem mais potencial para atingir a esperada aprendizagem significativa. Para o Ministério da Saúde, “a aprendizagem significativa acontece quando aprender uma novidade faz sentido para nós. Geralmente, isso ocorre quando a novidade responde a uma pergunta nossa ou quando o conhecimento novo é construído a partir de um diálogo com o que sabíamos antes" (Brasil, 2005a, p. 11).

Todavia, é importante estarmos atentos para que a ênfase na metodologia não coloque em segundo plano "una transformación en la cultura de 
salud" e continuemos a ensinar o mesmo de outra forma (Rovere, 2005, p. 170). O núcleo das questões que permeiam a educação na saúde, antes de ser metodológico, é epistemológico, ou seja, a concepção de saúde e doença e a integralidade da atenção (Cutolo, 2001).

Os resultados sintetizados no Diagrama 1 e discutidos a partir das tabelas 1, 2, 3 e 4 pretendem ser uma contribuição para o conhecimento na área das políticas públicas orientadas para a educação permanente num conceito ampliado. Os descritores propostos e submetidos à apreciação de especialistas e juízes representam um conjunto de possibilidades para orientar e sistematizar os programas e processos; representam também a validação das propostas governamentais a partir da opinião de profissionais comprometidos com a responsabilização pelo sistema de saúde.

\section{Considerações finais: construção do conceito}

A Organización Panamericana de la Salud (OPS), em 1978, já definia a educação continuada como um processo permanente de educação, que vem complementar a formação básica e que tem como principal objetivo atualizar e melhorar capacidades de pessoas ou grupos, frente às mudanças técnicas e científicas e as necessidades sociais (OPS, 1978). A Organización Mundial de la Salud (OMS), em 1982, referenda esta proposição ao enunciar que a educação continuada é um processo que inclui todas as experiências posteriores à formação inicial. Percebemos que tanto a OPS como a OMS atribuem o mesmo significado, ou seja, de sinônimos ou valor complementar às palavras continuada e permanente

Em 1980, por inspiração freireana, aparece o conceito de "competência continuada como processo ininterrupto de aperfeiçoamento, tanto de experiência de nível individual quanto coletiva" (Vieira, Roman e Luckesi, 1980, p. 47-48). Este processo ocorre pela tomada de consciência das limitações de si e do outro, o que também faz emergir as possibilidades de enfrentamento destas limitações, visando sua superação e transformação Esta abordagem pode contribuir para ampliar conceito de educação permanente, orientada para enriquecer a essência humana e suas subjetividades, em qualquer etapa da existência de todos os seres humanos e não somente de trabalhadores.

Não encontramos, nos documentos referenciais usados para este estudo, um conceito completo de educação permanente. Todavia, dada a amplitude da perspectiva ministerial, a escolha da terminologia 'educação permanente' é dada como justificativa para integrar as múltiplas abordagens pretendidas. Neste sentido, a educação permanente abrigaria, além da educação em serviço, a compreensão "no âmbito da formação técnica, de gra- 
duação e de pós-graduação; da organização do trabalho; da interação com as redes de gestão e de serviços de saúde e do controle social neste setor" (Brasil, 2003, p. 4).

Acreditando estar ampliando os conceitos apresentados, bem como a formulação do Ministério da Saúde, propomos um conceito de educação permanente que ultrapassa a continuidade de estudos após uma formação básica ou o preparo e atualização para o trabalho, mas adquire uma dimensão inclusiva e processual. Inclusiva na medida em que prevê a participação de todos os atores, ou seja, "indivíduos, grupos ou instituições capazes de interferir de forma ética e/ou política em uma determinada situação, de acordo com um projeto próprio" (Brasil, 2005a, p. 8). Processual porque, sem desqualificar as capacitações pontuais, investe na continuidade de desenvolvimento de projetos articulados entre instituições. Inspira-se também nas colocações de Moraes (2006, p. 396) que, ao recuperar historicamente o conceito de educação permanente, acontecendo ao longo da vida, refere que o mesmo "conferia centralidade à educação tanto em termos pedagógicos quanto como objeto de políticas sociais".

O conceito ampliado que propomos considera a educação permanente como direito de cidadania que inclui a produção, incorporação, reelaboração, aplicação e testagem de conhecimentos, habilidades, atitudes e tecnologias, através de um processo multidimensional de perspectivas e prioridades, efetivado na relação dialógica e participativa entre os diferentes saberes dos sujeitos sociais, negociada entre as partes envolvidas no processo de ensino e aprendizagem, desenvolvida a partir de projetos de curta, média e longa duração, promovendo a valorização da subjetividade, a cooperação, a solidariedade, a troca, a superação da realidade existente, para construção da realidade almejada e possível. Os espaços de interação desta educação incluem a vida cotidiana, a educação formal e informal, o preparo para o trabalho, a organização e controle social, a cultura e o lazer.

Com a convicção de que os resultados apresentados neste artigo podem contribuir para o delineamento de processos, projetos e propostas aderidas às políticas públicas de formação, capacitação, atualização e titulação de recursos humanos na área da saúde, não podemos nos furtar de apontar suas limitações. No que diz respeito à metodologia, entendemos que a mesma foi adequada para capturar e incorporar perspectivas de especialistas que estão convivendo com o processo de implementação das políticas públicas orientadas ao processo de educação permanente. Apesar de seu caráter eminentemente quantitativo, as fases de construção do diagrama se constituíram de diálogo presencial entre os pesquisadores e destes com os especialistas. O mesmo aconteceu na aplicação do 'método do júri'.

A análise do conjunto de descritores mostra que os mesmos podem ser mais detalhados na medida em que tenhamos a participação dos traba- 
lhadores, o que sugere a necessidade de continuidade do estudo. Esta continuidade está sendo concretizada na segunda etapa, em andamento, consultando todos os profissionais que atuam em atenção básica na região adstrita a este estudo. Pois, como bem colocado pela OPS/OMS (2002, p. 4), "la educación permanente se define desde el ámbito laboral y con el protagonismo del personal de salud".

\section{Notas}

1 Professora-pesquisadora do Programa de Mestrado em Saúde da Universidade do Vale do Itajaí (Univali), Itajaí, Brasil. Doutora em Enfermagem pela Universidade de São Paulo (USP).<saupe@amja.org.br>

Correspondência: Universidade do Vale do Itajaí, Centro de Ciências da Saúde, Programa de Pós-Graduação em Saúde, Rua Uruguai, 458, Bloco 27, $3^{\circ}$ andar, Centro, Itajaí, Santa Catarina, Brasil, CEP 88302-202.

2 Professor-pesquisador do Programa de Mestrado em Saúde da Universidade do Vale do Itajaí (Univali), Itajaí, Brasil. Doutor em Educação pela Universidade Federal de Santa Catarina (UFSC).<cutolo@univali.br>

3 Professora-pesquisadora do Programa de Mestrado em Saúde da Universidade do Vale do Itajaí (Univali), Itajaí, Brasil. Doutora em Enfermagem pela Universidade Federal de Santa Catarina (UFSC). <jusandri@univali.br>

4 Projeto de pesquisa submetido ao edital 49/2005, aprovado e financiado pelo CNPq conforme processo 402044/2005-3.

\section{Referências}

ALMEIDA, Marcio José de. Diretrizes curriculares nacionais para os cursos universitários da área da saúde. Londrina: Rede Unida, 2003.

BRANDÃO, Carlos Rodrigues. O que é educação. São Paulo: Brasiliense, 1993.

BRASIL. Ministério da Saúde. Políticas de formação e desenvolvimento para o SUS: caminhos para a educação permanente em saúde. Brasília, 18 de setembro de 2003. Disponívelem: <http://bvsms.saude.gov.br/ bvs/publicacoes>. Acesso em: 22 fev. 2007.

BRASIL. Ministério da Saúde. Portaria GM/MS n ${ }^{\circ}$ 198/2004, de 13 de fevereiro de 2004. Institui a Política Nacional de Educação Permanente em Saúde como estratégia do Sistema Único de Saúde para a formação e o desenvolvimento de trabalhadores para o setor e dá 
outras providências. Disponível em: $<$ http://portal.saude.gov.br/portal/sgtes $>$. Acesso em: 22 fev. 2007.

BRASIL. Ministério da Saúde. A educação permanente entra na roda: pólos de educação permanente em saúde - conceitos e caminhos a percorrer, 2005a. Disponível em: <http://bvsms.saude.gov.br/bvs /publicacoes/>. Acesso em: 22 fev. 2007.

BRASIL. Ministério da Saúde. Pro-saúde. Programa Nacional de Reorientação da Formação Profissional em Saúde, 2005b. Disponível em: <http://portal.saude.gov.br /portal/sgtes> Acesso em: 22 fev. 2007.

BRASIL. Ministério da Saúde. Secretaria de Gestão do Trabalho e da Educação na Saúde (SGTES). Departamento de Gestão da Educação na Saúde (Deges). 2007. Disponível em: <http://portal.saúde.gov.br/portal /sgtes>. Acesso em: 21 jul. 2007.

CECCIM, Ricardo Burg. Educação Permanente em Saúde: desafio ambicioso e necessário. Interface: Comunicação, Saúde, Educação, v. 9, n. 16, p. 161-168, set. 2004/fev. 2005.

CECCIM, Ricardo Burg; FEUERWERKER, Laura C. M. O quadrilátero da formação para a área da saúde: ensino, gestão, atenção e controle social. Physis: Revista de Saúde Coletiva, Rio de Janeiro, v. 14, n. 1, p. 41-65, 2004.

CUTOLO, Luiz Roberto Agea. Estilo de pensamento em educação médica: um estudo do currículo do curso de graduação em Medicina da UFSC. Tese de doutoradao, Florianópolis: Programa de Pós-Graduação em Educação, Universidade Federal de Santa Catarina, 2001.

DELEUZE, Gilles. Conversações. Rio de Janeiro: Editora 34, 1992.

FERRAZ, Fabiane. Educação permanente/ continuada no trabalho: um direito e uma necessidade para o desenvolvimento pessoal, profissional e institucional.
Dissertação de mestrado, Florianópolis: Curso de Pós-Graduação em Enfermagem, Universidade Federal de Santa Catarina, 2005.

FURTER, Pierre. 1974. Educação permanente $e$ desenvolvimento cultural. Petrópolis: Vozes.

HARPER, Babette et al. Cuidado escola! Desigualdades, domesticação e algumas saídas. São Paulo: Brasiliense, 1980.

MERHY, Emerson Elias. O desafio que a educação permanente tem em si: a pedagogia da implicação. Interface: Comunicação, Saúde, Educação, v. 9, n. 16, p. 172-174, set. 2004/fev. 2005.

MORAES, Sylvia Vidigal. Educação permanente: direito de cidadania, responsabilidade do Estado. Trabalho, Educação e Saúde, v. 4, n. 2, p. 395-416, 2006.

ORGANIZACIÓN MUNDIAL DE LA SALUD (OMS). Continuando la educación de los trabajadores de salud: principio e guías para el desarrollo de un sistema. Genebra, 1982.

ORGANIZACIÓN PANAMERICANA DE LA SALUD (OPS). Proyecto regional de educación permanente en salud. Washington, 1978.

ORGANIZACIÓN PANAMERICANA DE LA SALUD. ORGANIZACIÓN MUNDIAL DE LA SALUD. Programa de desarrollo de recursos humanos: la capacitación del personal de los servicios de salud en proyectos relacionados con los procesos de reforma sectorial, 2002. Serie Observatorio de Recursos Humanos de Salud $n^{\circ} 3$. Disponível em: <www.opas.org.br/rh /admin/documentos/ACF33.pdf $>$. Acesso em: 31 jul 2007.

PEREIRA, Luciana Alves; MONTEIRO, Fatículo Andreo. Boletim Informativo/ eletrônico, Rede Unida, n. 17, 23 fev. 2004. Disponível em: <www.redeunida.org.br /inrede/inreden17.asp > Acesso em: $22 \mathrm{fev}$. 2007. 
RIBEIRO, Eliana Claudia de Otero; MOTTA, José Inácio Jardim. Educação permanente como estratégia na reorganização dos serviços de saúde. Divulg. saúde debate, v. 12, p. 39-44, jul. 1996. Boletim Eletrônico. Disponível: <www.redeunida. org. br/arquivos/educacao.rtf $>$. Acesso em: 22 fev. 2007.

SAUPE, Rosita et al. Competência dos profissionais da saúde para o trabalho interdisciplinar. Interface: Comunicação, Saúde, Educação, v. 9, n. 18, p.521-536, 2005.

Conceito de competência: validação por profissionais de saúde. Saúde em Revista, v. 8, n. 18, p. 31-37, 2006.

SPÍNOLA, Moacyr Roberto; PEREIRA, Evaristo Manoel. Avaliação do Programa Imposto de Renda - 77. Projeção, n. 19, p. 2-11, 1977. Suplemento especial.
ROVERE, Mario. Comentarios estimulados por la lectura del artículo “Educação Permanente em Saúde: desafio ambicioso e necessário". Interface: Comunicação, Saúde, Educação, v. 9, n. 16, p. 169-171, set. 2004/fev. 2005.

VIEIRA, Therezinha Teixeira; ROMAN, Alaíde Vieira de; LUCKESI, Maria Antonieta Vasconcelos. A competência continuada e a assistência de enfermagem. In: CONGRESSO BRASILEIRO DE ENFERMAGEM, 32, 1-7 jun. 1980, Brasília. Anais... Brasília: ABEn, 1980.

Recebido em 29/05/2007

Aprovado em 04/09/2007 